\title{
The Calculation of Thermal Resistance for Forced Air Cooling
}

\author{
Jian Zhang ${ }^{1}$, Donglai Zhang ${ }^{1, *}$ \\ ${ }^{1}$ Nanshan Xili University Town HIT, Shenzhen, China
}

\begin{abstract}
Efficient heat dissipation of high power and a high heat flux density for power electronic devices are demanded, along with high reliability, high power density, miniaturization, and a light weight. One solution is to transfer heat from the electronic device to the surrounding environment rapidly by heat sink, and the main basis for the choice of heat sink is its thermal resistance. Therefore the thermal resistance calculation for a heat sink is key to its design in the cooling system of power electronic equipment. Based on an analysis of forced air cooling, a thermal resistance model of a heat sink is developed; a simple, accurate calculation method for evaluation of the thermal resistance in forced air cooling heat sink is proposed in this work. The calculation method is verified by an ANSYS simulation; the validity and accuracy of the method is verified by the experimental results found herein.
\end{abstract}

\section{Introduction}

With the expansion of their range of application, the diversification of their functionality, the improvements in their integration, and their increasingly harsh working environment, power electronic device reliability design is required. An important factor affecting the reliability of electronic equipment is the thermal design thereof. The junction temperature of electronic devices will increase if heat inside the electronic devices cannot be transferred away timeously. The performance of an electronic device will diminish, or it may even fail, when the working junction temperature exceeds the maximum allowed [1]. The reduction in performance, or failure, of such electronic devices will cause changes in the circuit parameters resulting in interference. The thermal design of electronic equipment items mainly includes the selection of cooling mode and cooling medium, flow rate and flow control, the material used in its heat sink(s) and the structural design thereof, etc. Common cooling methods include: natural cooling, forced air cooling, liquid cooling, etc. [2]. Natural cooling cannot meet the demand of high-power electronic devices when the heat flux density exceeds $0.8 \mathrm{~W} / \mathrm{cm}^{2}$. Under normal conditions, the effect of forced air cooling is between five and 10 times better than natural cooling. Although the effect of forced air cooling is less than liquid cooling, its complexity, cost, volume, and weight are far lower than those need for liquid cooling. The reliability of forced air cooling is far higher than that of liquid cooling because liquid cooling needs to consider the replacement of coolant. The maintenance of a liquid cooling system is thus more difficult. Forced air cooling heat dissipation systems are therefore widely used due to their advantages which include: low cost, high reliability, and simplicity in high-power electronic devices. Forced air cooling is the main means of cooling used from systems operating at hundreds of watts, to several hundred megawatts.

Thermal resistance from the heat sink to its surroundings is the key parameter reflecting the thermal performance of a heat sink. The thermal resistance can be improved by design optimization according to the thermal resistance equivalent circuit of a forced air cooling system. The proportion of this resistance in the total thermal resistance is the biggest in the path of heat transfer for such electronic items [3]. Therefore the key to thermal structure optimization in such cooling systems is to reduce the thermal resistance of the heat sink. The structure parameters and cooling conditions are main factors affecting the thermal resistance of a heat sink. Optimization of the structure parameters is one of the main methods used when minimizing thermal resistance and improving the cooling performance. The shape optimization of heat sink is studied in [4-5]. The effect of structure parameters, such as fin spacing, fin thickness and the number of fins on the device junction temperature has also been analyzed [6-11]. Therefore, derivation of an expression for the calculation of thermal resistance has laid a foundation for the thermal structure optimization of a cooling system, in which, the objective is minimization of the thermal resistance of the heat sink.

The mostly commonly used formula of thermal resistance of heat sink in forced air cooling is [2]:

$$
R_{\theta(s-a)}=(\sqrt{10 / k d}+650 / A) C_{1} C_{2} C_{3}
$$

This formula can only part-describe the effect of some of the structure parameters on heat dissipation according to (1), and especially with regard to the thermal design of high-power electronic devices for which the error is greater. So, heat sink is simplified until it is deemed to consist of many pieces of metal plate [12-13], and a calculation formula for the thermal resistance is derived for use under forced air cooling conditions. The effect of the base plate and gap between the fins of heat sink was not revealed, and the error was bigger in high-power forced air cooling system. Only the gap between the fins is considered when analyzing and optimizing the thermal resistance of a heat sink [14-15], and a more accurate calculation thermal resistance is derived by considering the effects of the base plate and gap between the fins [1622]; however, the calculation method for fin resistance and fin spacing resistance is too complex. It is not conductive to the thermal structure optimization of a heat sink using thermal resistance minimization as its objective function. An easier calculation method for finding the thermal resistance ahead of its optimization is proposed based on this problem; the method is beneficial to the optimization of the structure parameters of a heat sink and the external cooling conditions applicable to the 
electronic equipment served. The structure parameters describe the overall shape of the heat sink.

\section{Calculation method of thermal resistance of forced air cooling heat sink}

The model for the thermal resistance of an electronic device is shown in Fig.1. There are two paths for heat transfer when the power electronic device is operational. The first sees heat transferred from core to shell before being dissipated to the surroundings by convection and radiation. The second comprises three stages: first, the heat is transferred from core to shell, then the heat is transferred to the heat sink which is in contact with the shell, and finally the heat is dissipated to the surroundings by convection and radiation. Thermal resistance is the key parameter reflecting the ability to dissipate heat along both paths. The equivalent circuit of thermal resistance of a power electronic device is shown in Fig.2. The corresponding resistance along the first path is a junction to shell resistance $R_{\theta(j-c)}$ and a shell to environment resistance $R_{\theta(c-a)}$. The corresponding resistances for the three heat transferring processes of the second path are: a junction to shell resistance $R_{\theta(j-c)}$, a shell to heat sink resistance $R_{\theta(c-s)}$, and a heat sink to environment resistance $R_{\theta(s-a)}$. Therefore the total resistance of an electronic device is determined as:

$$
R_{\theta(j-a)}=R_{\theta(j-c)}+\frac{\left(R_{\theta(c-s)}+R_{\theta(s-a)}\right) \cdot R_{\theta(c-a)}}{R_{\theta(c-s)}+R_{\theta(s-a)}+R_{\theta(c-a)}}
$$

Figure 1. Model of thermal resistance of an electronic device.

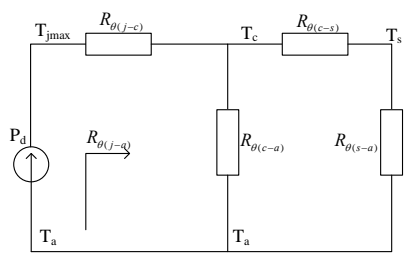

Figure 2. Thermal equivalent circuit of a power electronic device.

The junction to shell resistance $R_{\theta(j-c)}$ depends on manufacturer technology and packaging materials in (2), and it can be obtained from the product manual. Shellheat sink resistance $R_{\theta(c-s)}$ is mainly decided by the size and quality of the shell and heat sink. Enough pressure must be applied to the interface between the shell and heat sink during its installation. The heat sink to environment resistance $R_{\theta(s-a)}$ is related to the structure, materials use in the heat sink, and external cooling environment. The resistance from shell to environment is defined as $R_{\theta(c-a)}$. The heat flux through an electronic device installed on a heat sink is mainly transferred from the junction to the bottom of such devices, and then heat is transferred to the surroundings. $R_{\theta(c-a)}$ is much greater than $R_{\theta(c-s)}$ and $R_{\theta(s-a)}$, and it can be ignored when it is parallel with $R_{\theta(c-s)}$ and $R_{\theta(s-a)}$. Therefore the main resistance on the path of heat transfer is $R_{\theta(s-a)}$ : this can be minimized by changing the structure parameters of the heat sink and external cooling environment. The calculation of thermal resistance is a prerequisite for the reasonable and effective thermal management of power electronic devices.

The combination heat sink used in high-power electronic equipment cooling systems is analyzed here as an example. The structure of a heat sink is shown in Fig.3. The equivalent circuit diagram for the thermal resistance for each cooling channel from heat sink to the external environment is shown in Fig.4. The calculation process (Fig. 4) is as follows; the resistance of the heat sink is divided into four parts: the conductive thermal resistance of the top base plate, the conductive thermal resistance of the fins, the conductive thermal resistance of the bottom base plate, and the convective thermal resistance of the fins. It is represented by:

$$
\begin{gathered}
R_{\text {total }}=R_{\mathrm{th}, b 1}+\frac{R_{t h, f i n}}{2 N}+R_{t h, b 2}+R_{t h, A} \\
R_{\mathrm{th}, b 1}=\frac{l_{1}}{k W L} \\
R_{t h, f i n}=\frac{H-l_{1}-l_{2}}{k t L} \\
R_{\mathrm{th}, b 2}=\frac{l_{2}}{k W L} \\
R_{\mathrm{th}, A}=\frac{1}{h A}
\end{gathered}
$$

In (3) to (7) $R_{\text {total }}$ is the total resistance of the heat sink, $R_{t h, b l}$ is the conduction thermal resistance of the top base plate, $R_{t h, f i n}$ is the conduction thermal resistance of the fins, which is the parallel resistance of $N$ fins, $R_{t h, b 2}$ is the conduction thermal resistance of the bottom base plate, $R_{t h, A}$ is the convective thermal resistance of the fins, which is the parallel resistance of two sides of the cooling channel, $k$ is the thermal conductivity of the heat sink material(s), $l_{l}$ is the thickness of the top base plate, $l_{2}$ is the thickness of the bottom base plate, $W$ is the width of the heat sink, $L$ is the length of the heat sink, $H$ is the total height of the heat sink, and $t$ is the fin thickness. 


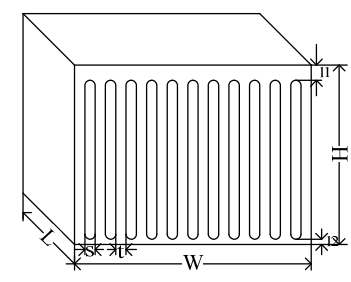

Figure 3. Structure diagram of combination heat sink.

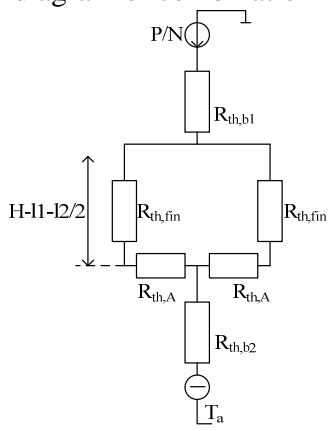

Figure 4. Equivalent circuit diagram of the thermal resistance of an electronic device.

The convective heat transfer coefficient in (7) is calculated as reported elsewhere [23]

$$
\begin{gathered}
h=\frac{N_{u} \cdot k_{\text {air }}}{L} \\
N_{u}=S_{t} \cdot \mathrm{R}_{\mathrm{e}} \cdot \operatorname{Pr} \\
S_{t}=\frac{0.0296\left(\mathrm{R}_{\mathrm{e}}\right)^{-1 / 5}}{1+1.52 \times\left(\mathrm{R}_{\mathrm{e}}\right)^{-1 / 10}(\mathrm{Pr}-1)} \\
\mathrm{R}_{\mathrm{e}}=\frac{v \cdot L}{v}
\end{gathered}
$$

In (8) to (11), $K_{\text {air }}, P_{r}$ and $v$ are the thermal conductivity of the cooling air, the prandtl number, and the flow viscosity of the cooling air respectively. The values are $0.0234 \mathrm{~W} / \mathrm{mK}, 0.7$ and $1.91 \times 10^{-5} \mathrm{~m}^{2} / \mathrm{s}$ in atmospheric conditions at a temperature of $40^{\circ} \mathrm{C}$. $S_{t}$ is the Stanton number, $v$ is the average channel velocity, $N_{u}$ is the Nusselt number, and $R_{e}$ is Reynolds number.

The convective thermal resistance for a cooling channel on the heat sink is derived by:

$$
R_{\mathrm{th}, A}=\frac{1-0.152(v \cdot L)^{-\frac{1}{10}}}{5.12(v \cdot L)^{\frac{4}{5}}\left(H-l_{1}-l_{2}+s\right) \cdot 2 N}
$$

In (12) $s$ is the fin spacing.

Therefore the calculation expression for a combination heat sink is:

$$
\begin{aligned}
& R_{\text {total }}=\frac{l_{1}}{k W L}+\frac{H-l_{1}-l_{2}}{2 N \cdot k t L}+\frac{l_{2}}{k W L}+ \\
& \frac{1-0.152(v \cdot L)^{-\frac{1}{10}}}{5.12(v \cdot L)^{\frac{4}{5}}\left(H-l_{1}-l_{2}+s\right) \cdot 2 N}
\end{aligned}
$$

\section{Simulation}

The calculated results for a combination heat sink on electronic load equipment are chosen as an example to verify the proposed method of calculation of the thermal resistance. The total power loss of an IGBT when the electronic load equipment is in working normally is
$P=4000 \mathrm{~W}$. The material used in the heat sink is 6063 aluminum. The geometry and dimensions of this combination heat sink are shown in Fig. 5. Its parameters are $H=0.15 \mathrm{~m}, \quad l_{l}=0.023 \mathrm{~m}, \quad l_{2}=0.0062 \mathrm{~m}, \quad N=136$, $W=0.5406 \mathrm{~m}, L=0.54 \mathrm{~m}, t=0.001 \mathrm{~m}$, and $s=0.0032 \mathrm{~m}$. IGBT is chosen as the electronic device simulated here; its thermal resistance parameters are shown in Table I.

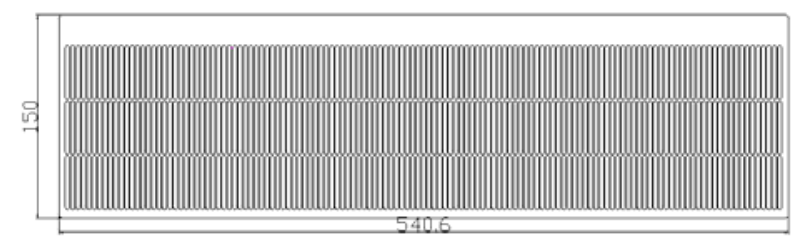

Figure 5. Geometry dimension of heat sink.

The thermal resistance of the heat sink shown in Fig.5 is $0.0062 \mathrm{~K} / \mathrm{W}$ according to the results from (13); the relationship between thermal resistance, temperature change, and power loss is as follows:

$$
R_{\text {total }}=\frac{\Delta t}{P}
$$

So the temperature rise of heat sink surface is $24.8^{\circ} \mathrm{C}$.

The finite element simulation results for a steady temperature distribution, when the electronic load is working in an ambient temperature of $40^{\circ} \mathrm{C}$ are shown in Fig.6; the maximum temperature of the shell for IGBT when the electronic load equipment reached steady thermal equilibrium is $70.8^{\circ} \mathrm{C}$. The maximum surface temperature of the heat sink is $64.8^{\circ} \mathrm{C}$ according to (14), and Table I. The maximum temperature increase in the heat sink is $24.8^{\circ} \mathrm{C}$, the results are agreed with calculated results of thermal resistance values.

Table 1. Thermal resistance parameters for IGBT.

\begin{tabular}{ccc}
\hline $\begin{array}{c}\text { Name of thermal } \\
\text { resistance }\end{array}$ & Name of device & $\begin{array}{c}\text { Vales of thermal } \\
\text { resistance }{ }^{\circ} \mathbf{C} / \mathbf{W}\end{array}$ \\
\hline $\begin{array}{c}\text { Junction-shell } \\
\text { resistance } R_{\text {thjc }}\end{array}$ & transistor & 0.007 \\
$\begin{array}{c}\text { Junction-shell } \\
\text { resistance } R_{\text {thjc }}\end{array}$ & diode & 0.012 \\
$\begin{array}{c}\text { Shell-heat sink } \\
\text { resistance } R_{\text {thcs }}\end{array}$ & module & 0.006 \\
\hline & & \\
\hline
\end{tabular}

Figure 6. Steady temperature distribution of electronic load.

\section{Experimental work}

The experimental platform and temperature test system when the electronic load equipment is working on normally load are shown in Fig.7. The anemometer (type DT620), thermometer (type TES1314) and data recorder (type LR8401-02) are used to measure the air velocity at the inlet and outlet, and the surface temperature of the 
heat sink, respectively. Fig.8 shows the transient temperatures at a total power loss of $4 \mathrm{~kW}$ and when the ambient temperature is $T_{a}=22^{\circ} \mathrm{C}$. The maximum surface temperature of the heat sink is $47^{\circ} \mathrm{C}$ when the cooling system reached thermal equilibrium. The experimental results agreed with those calculatied and simulated. The accuracy and effectiveness of the proposed calculation method of the thermal resistance of this forced air cooling heat sink were thus verified.

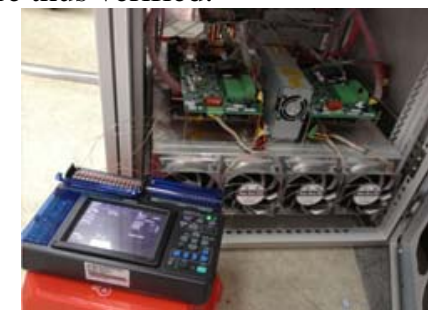

Figure 7. The experimental platform

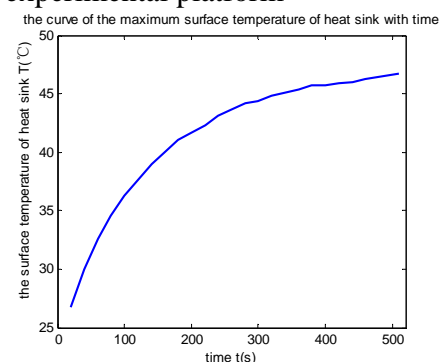

Figure 8. Surface temperature rise on the heat sink.

\section{Conclusion}

A simple and accurate method for the calculation of thermal resistance is proposed on the basis of the problem of minimizing the thermal resistance of a heat sink under forced air cooling conditions. The common combination heat sink in a forced air cooling system is analyzed as an example. The total thermal resistance of the heat sink is divided into four parts: the conductive thermal resistance of the top base plate, the conductive thermal resistance of its fins, the convective thermal resistance of its fins, and the conductive thermal resistance of the bottom base plate. The calculation is verified by simulation and experimental results. The results show that the proposed method of calculation of thermal resistance is both accurate and effective. The method provides a reliable basis for the thermo-structural optimization of a heat sink under forced air cooling, and other, conditions.

\section{References}

[1] J. Zhang, D. L. Zhang, IEEE Trans. Compon. Packag. Technol., 3 (2013) 710-717

[2] Q. L. Zheng, W. X. Geng, Publishing House of Electronics Indus, (1996)

[3] D. Jang, S. H. Yu, K. S. Lee, Int. J. Heat Mass Transf., 55 (2012) 515-521

[4] A. Shah, B. G. Sammakia, H. Srihari, IEEE Trans. Compon. Packag. Technol., 27 (2004) 710-717

[5] U. Drofenik, J. W. Kolar, Power Conversion Conference - Nagoya, (2007) 1189-1194
[6] Y. Luo, H. Chen, SAE China, (2009)

[7] N. Han, S. P. Wang, Computer Engineering \& Science, 23 (2001) 66-68

[8] J. X. Zhang, P. J. Niu, H. Y. Li, L. G. Sun, Chin. J. Lumin., 34 (2013) 516-522

[9] C. J. Zhou, Ms. D. dissertation, (2012)

[10]A. Bar-Cohen, W. M. Rohsenow, J. Heat Transf., 106 (1984) 116-123

[11]J. R. Culham, Y. S. Muzychka, in Proc. IEEE Intersociety Conf. Thermal Phenomena (2000) 159165

[12]Y. W. Zhu, X. D. Lu, Components and Modules, (2009) 47-51

[13]T. Zhou, X. D. Lul, J. Bohai University Natural Science Edition, 32 (2011) 228-235

[14] J. X. Zhang, P. J. Niu, Z. G. Wu, J. X. Wang, H. Y. Li, Trans. China Electrotechnical Society, 29 (2014) 136-142

[15]W. B. Krueger, A. Bar-Cohen, IEEE Trans. Compon. Packag. Technol., 27 (2004) 417-425

[16]D. Lv, W. W. Shen, K. Y. Shi, M. Chen, D. H. Xu, J. Power Supply, (2012) 42-46

[17]P. Q. Ning, G.Y. Lei, F. Wang, Applied Power Electronics Conference and Exposition, TwentyThird Annual IEEE, (2008) 192-198

[18]U. Drofenik, A. Stupar, J. W. Kolar, IEEE Trans. Compon. Packag. Manuf. Technol., 1 (2011) 528535

[19]U. Drofenik, A. Stupar, J. W. Kolar, Proc. of 4th Int. Conf. on Integrated Power Systems, (2006) 323-328

[20]H. L. Su, B. J. Qin, J. Eng. Design, 14 (2007) 31-34

[21]U. Drofenik, G. Laimer, J. W. Kolar, in Proc. Int. PCIM Eur. Conf., (2005) 608-619

[22]J. R. Culham, Y. S. Muzychka, IEEE Trans. Comp. Packag. Technol., 24 (2001) 159-165

[23]E. R. G., R. M., Science Press, (1965) 